\title{
PENGEMBANGAN INOVASI PRODUK BERKELANJUTAN PADA UKM BU ERMA DI JAMBI
}

\author{
Rodhiah $^{1^{*}}$, Agustina Ika Widyani ${ }^{2}$, Septia Winduwati ${ }^{3}$ \\ Program Studi Manajemen, Fakultas Ekonomi dan Bisnis, Univertsitas Tarumanagara Jakarta \\ ${ }^{2}$ Program Studi DKV,Fakultas FSRD,Universitas Tarumanagara Jakarta \\ ${ }^{3}$ Program Studi Ilmu Komunikasi, Fakultas Komunikasi Universitas Tarumanagara Jakarta \\ E-mail: ${ }^{1)}$ rodhiah@,fe.untar.ac.id, ${ }^{2)}$ agustinai@fsrd.untar.ac.id, ${ }^{3)}$ septiaw@fitkom.untar.ac.id
}

\begin{abstract}
Abstrak
Seorang wirausahawan harus selalu melakukan inovasi, agar produk yang diciptakan dapat menghadapi kondisi persaingan yang semakin berat. Mitra yang menjadi tempat kegiatan adalah UKM bu Erma, yang berlokasi di Jambi. Dari hasil observasi awal secara online, terlihat masalah utama yang dihadapi mitra adalah inovasi, belum adanya pemahaman mitra tentang pentingnya strategi inovasi yang berkelanjutan dalam melakukan bisnis. Kondisi ini terjadi karena mitra kurang memiliki pengetahuan tentang inovasi. Sehingga produk yang dihasilkan mitra monoton dan kurang berinovatif bahkan banyak yang serupa dengan pesaing. Metode kegiatan dilakukan dengan mensosialisasikan atau memberikan pelatihan pada mitra secara daring melalui zoom. Penyampaian materei disajikan dalam bentuk PPT terkait dengan strategi inovasi. Hasil kegiatan menunjukkan pembekalan pengetahuan tentang inovasi telah berjalan dengan lancar, mitra bersemangat dalam mendengarkan materi dan berdiskusi dengan Tim PKM. Selanjutnya melalui inovasi, mitra dapat menciptakan produk menjadi produk yang dapat meningkatkan keberlanjutan usaha.
\end{abstract}

Kata kunci: Inovasi, Pelatihan, Produk, Keberlanjutan Usaha.

\begin{abstract}
An entrepreneur must always innovate, so that the products created can face increasingly tough competitive conditions. The partner who became the venue for the activity was Ms. Erma's SME, which is located in Jambi. From the results of initial online observations, it can be seen that the main problem faced by partners is innovation, there is no partner understanding about the importance of sustainable innovation strategies in doing business. This condition occurs because partners lack knowledge about innovation. So that the products produced by partners are monotonous and less innovative, even many are similar to competitors. The activity method is carried out by socializing or providing training to partners online via Zoom. Submission of materials is presented in the form of PPT related to the innovation strategy. The results of the activity showed that the provision of knowledge about innovation had run smoothly, partners were enthusiastic in listening to the material and discussing with the PKM (Student Creativity Program) Team. Furthermore, through innovation, partners can create products into products that can improve business sustainability.
\end{abstract}

Keywords: Innovation, Training, Products, Business Sustainability.

\section{PENDAHULUAN}

Inovasi dari usaha kecil dan menengah mendorong pertumbuhan berkelanjutan. Kemampuan manajemen berinovasi perlu didukung oleh kualitas produk yang dihasilkan, dan sinergi pemasaran (Mahmood et al., 2013). Selain itu kinerja perusahaan dapat 


\section{PORTAL RISET DAN INOVASI PENGABDIAN MASYARAKAT (PRIMA) \\ VOLUME 1 ISSUE 1 (2021)}

ditingkatkan dengan inovasi (Azadehdel et al., 2013; Mahmood et al., 2013)produk inovasi desain yang lebih baik dan lebih menarik mendorong pertumbuhan penjualan (Dirisu et al., 2013). Demikian pula, kinerja usaha kecil dan menengah menjadi bagus dengan adanya kemampuan inovasi (Sulistyo, 2016).

Kunci untuk kinerja bisnis jangka panjang sangat ditentukan oleh keunggulan kompetitif melalui produk yang inovatif. Kemampuan inovasi perusahaan akan memberikan nilai kepada pelanggan secara ebih baik dari pesaing dan dapat menciptakan keunggulan kompetitif.

Edukasi mengenai inovasi produk pada pada produk UKM sangat penting dilakukan agar dapat memberikan nilai tambah atas produkyang dihasilkan. Hal tersebut tentunya akan dapat menambah pendapatan. Inovasi produk dapat diartikan sebagai upaya yang dilakukan pelaku usaha pembuat produk untuk memperbaiki, meningkatkan, dan mengembangkan produk yang diproduksi (Fakhriyyah \& Wulandari, 2021). Han et al. dalam Ikhsani (2016) menyebutkan bahwa tujuan utama dari inovasi produk adalah untuk memenuhi permintaan pasar sehingga produk inovasi merupakan salah satu yang dapat digunakan sebagai keunggulan bersaing bagi perusahaan.

Seiring berjalannya waktu dan dengan dengan kondisi pandemic covid-19 seperti saat ini, maka tidak salah jika satu pertimbangan utama dalam mendirikan sebuah usaha adalah adanya konsep produk yang penuh dengan inovatif. Namun masalahnya tidak semua Usaha Kecil Menengah (UKM) di Indonesia memiliki dan memikirkan hal ini. Hal ini terjadi karena memang tidak ada model inovasi pengembangan konsep produk yang benar-benar bisa dijadikan pedoman oleh para pelaku UKM di Indonesia. Mitra yang menjadi tempat kegiatan PKM bergerak dalam usaha kuliner dengan merek bu Erma, berbagai jenis produk makanan yang dijual bu Ermawati yaitu peyek, dodol agar-agar, donat kentang, dan pempek.Namun demikian inovasi produk yang dilakukan belum dilakukan secara optimal, kondisi tersebut akibat dari minimnya pengetahuan bu Ermawati dalam hal tentang pengembangan inovasi produk. Untuk itu tujuan kegiatan PKM membekali pengetahuan bu Ermawati tentang inovasi, dan aktivitas yang perlu dilakukan dalam melakukan inovasi produk.

Inovasi adalah suatu penemuan baru yang berbeda dari yang sudah ada atau yang sudah dikenal sebelumnya. Seseorang yang inovatif akan selalu berupaya melakukan perbaikan, menyajikan sesuatu yang baru/unik yang berbeda dengan yang sudah ada. Berdasarkan observasi dan diskusi dengan mitra permasalahan utama secara spesifik berkaitan dengan pembekalan pengetahuan tentang inovasi. Alasan mengapa perlu dilakukannya kegiatan ini adalah.: 1) Optimalisasi produk yang lebih unggul dari pesaing, 2) Kurangnya pengetahuan mitra tentang pentingnya inovasi. Jika permasahan mitra dibiarkan akan berefek pada hasil produk yang belum inovatif, dan lemahnya keberlanjutan usaha. Oleh karena itu, Tim PKM berkeinginan mentransfer pengetahuan inovasi, agar mitra memahami pentingnya menciptakan produk yang lebih berinovasi. Permasalahn mitra dapat dikempokkan menjadi:

1. Bagaimana memperkenalkan pengetahuan tentang inovasi pada pemilik usaha

2. Bagaimana memperkenalkan aktivitas yang perlu dilakukan agar dapat menciptakan produk yang lebih berinovatif

Berdasarkan latar belakang tersebut, solusi yang ditargetkan setelah selesainya kegiatan pengabdian masyarakat ini terkait dengan pembekalan pengetahuan inovasi produk. 
Pelatihan dan edukasi (trainning dan education) merupakan agenda penting dalam implementasi kegiatan, meliputi: 1). Pembekalan strategi inovasi, 2). Aktivitas inovasi produk, 3) Peluang, tantangan dan hambatan dalam melakukan inovasi.

\section{METODE PENELITIAN}

Langkah-Langkah/Tahapan Pelaksanaan

Berdasarkan permasalahan yang dihadapi bu Emawati dalam mengelola usaha, Maka langkah-langkah/tahapan pelaksanaan pelatihan yang perlu dilakukan:.

1) Megidentifikasi Sosial-ekonomi pemilik, termasuk produk yang yang selama ini sudah dihasilkan.

2) Mengidentifikasi permasalahan yang dihadapi selama melakukan usaha

3) Merancang materi yang akan disampaikan ke mitra

4) Melakukan pembuatan materi, pelatihan

5) Implementasi materi: secara daring

\section{HASIL DAN PEMBAHASAN}

$\mathrm{Bu}$ Erma merupakan usaha industri kecil rumah tangga berdiri sejak tahun 2017 yang didirikan oleh $\mathrm{Bu}$ Ermawati. Bu Erma merupakan jenis usaha kuliner yang menawarkan peyek, dodol agar-agar, donat kentang, dan pempek dalam kemasan plastik. Dikarenakan pandemi Covid-19, Bu Erma membuat keputusan dengan menjual peyek dan dodol agaragar. Usaha bu Ermawati berlokasi di Perumahan Permata Regency RT.02 Kel. Kenali Asam Bawah Kec. Kota Baru Jambi. Bu Erma bekerja seorang diri dan terkadang dibantu oleh keponakannya, apabila pesanannya ramai. Awalnya produk yang ditawarkan oleh usaha $\mathrm{Bu}$ Erma ada 4 macam, yaitu: peyek, dodol agar-agar, donat kentang, dan pempek. Semenjak covid-19, produk yang ditawarkan oleh Bu Erma hanya ada peyek dan dodol agar-agar.

Produk yang hasilkan bu Erma cukup memiliki variasi, Beberapa contoh produk yang dijual adalah sebagai berikut:
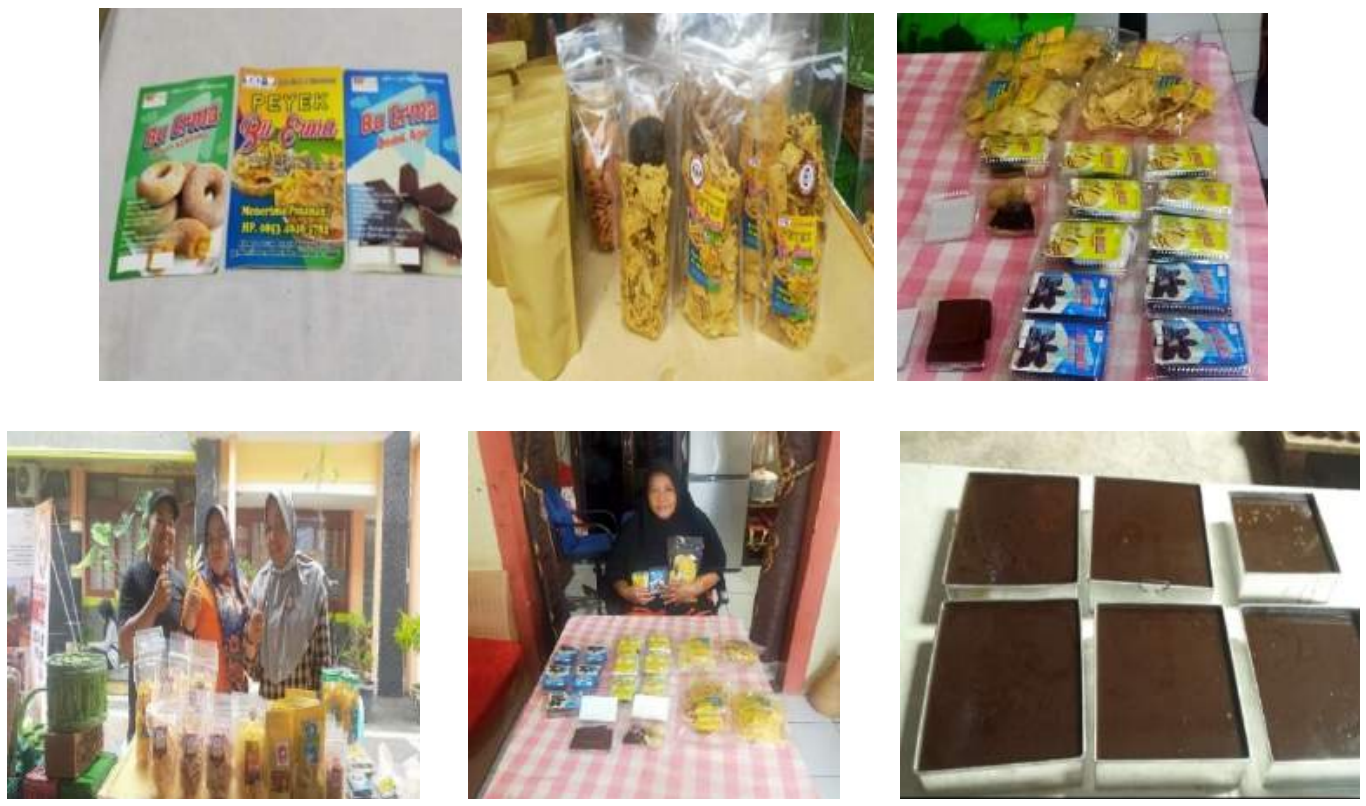

Gambar 1 Produk yang dihasilkan Mitra 


\section{PORTAL RISET DAN INOVASI PENGABDIAN MASYARAKAT (PRIMA) \\ VOLUME 1 ISSUE 1 (2021)}

\subsection{Model IPTEKS Yang Ditransper Kepada Mitra}

Proses pengembangan inovatif terdiri dari tiga lapisan proses yang saling terkait Mazzarol T. (2011) pengembangan kompetensi organisasi, dengan asumsi transformasi sumber daya menjadi kompetensi organisasi yang digunakan untuk mengusulkan penawaran pasar (Drucker, 2012), menggunakan kemampuan yang terkait dengan mencari sumber daya, konfigurasi sumber daya dan pengembangan penawaran pasar; (2) pengembangan konsep bisnis, dengan asumsi transformasi pengetahuan tentang pasar peluang ke dalam penawaran pasar berdasarkan model bisnis yang kompetitif, menggunakan kemampuan yang terkait dengan pencarian peluang pasar, mencari sumber keuntungan dan pengembangan penawaran pasar; (3) pengembangan konsep produk, yang digunakan di dalam produk inovatif, menggunakan kemampuan yang berkaitan dengan mencari pengetahuan teknologi, mencari aplikasi pengetahuan dan penerapan pengetahuan.

Dalam kegiatan Pelatihan, Ipteks yang ditransfer kepada mitra meliputi pemahaman dalam aktivitas produk inovatif yang terdiri dari 3 aktivitas, yaitu:

1) Tahap pertama yaitu mencari ilmu tentang teknologi yang berhubungan dengan produk inovatif yang akan diproduksi, hasil dari proses ini, UKM akan mendapatkan pengetahuan dan ilmu tentang teknologi terkini.

2) Tahap kedua ada proses mencari bagaimana memanfaatkan atau mengeksploitasi ilmu atau pengetahuan tentang teknologi yang telah didapatkan pada tahap pertama pada kerangka produk inovasi yang bersifat teknis atau non-teknis.

3) Tahap ketiga, ada proses penerapan ilmu atau pengetahuan tentang teknologi yang sudah diadapatkan pada produk baru yang sifatnya nanti akan menghasilkan produk inovatif dan sustainable. Sebelum munculnya produk baru yang sustainable, maka harus diukur terlebih dahulu, efisiensi dan efisiasi dari produk baru tersebut. Sehingga inilah hasil akhir kerangka kerja efisien yang akan membantu menghasilkan produk inovatif dimana produk tersebut akan meningkatkan sustainable development bagi mitra dalam menjalankan bisnis yang unggul dari pesaing. Berikut dokumentasi pada saat penyampaian materi sosialisasi.

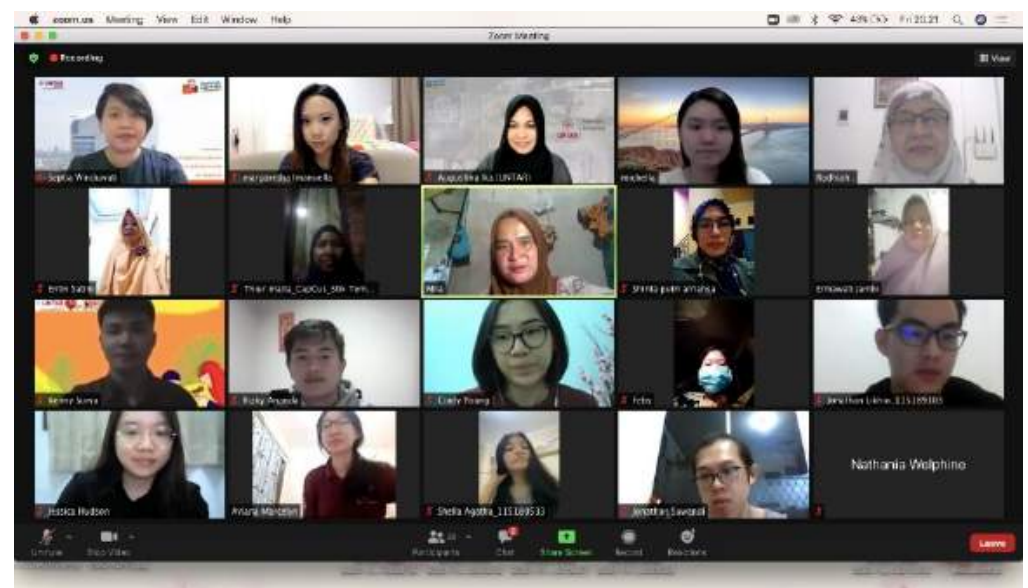

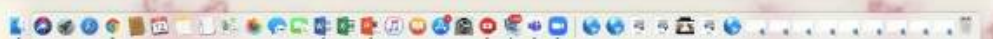

Gambar 2 Dokumentasi saat penyampaian Materi Inovasi 


\section{KESIMPULAN} dalam

Menjalankan sebuah usaha tak akan terlepas dari permasalahan persaingan, dan upaya

1. Pelatihan tentang inovasi diberikan dengan cara mensosialisasikan kepada mitra antar lain meliputi pengertian inovasi, alasan perlunya inovasi, prinsip inovasi, sifat inovasi,pengaruh inovasi, sustainable development, telah berjalan dengan lancar

2. Inovasi memiliki prinsip yang intinya sebagai keharusan dan larangan yang harus diperhatikan. Dengan demikian batik Setu perlu mempunyai disiplin inovasi yang dapat memeriksa secara sitematik terhadap perubahan yang dapat memberikan peluang.

3. Inovasi mempunyai lima sifat sebagai ciri yang khas dan tiga persyaratan yang menuntut kerja keras dari inovator. Juga inovasi mempunyai keputusan yang berbeda dengan cara membuat keputusan yang lainnya, yaitu keputusan individu dan keputusan otoritas.

\section{Ucapan Terima Kasih}

Terima kasih kepada LPPM Untar yang telah memberikan pendanaan pada kegiatan PKM sehingga dapat diselesaikan tepat pada waktunya. Terima kasih juga kepada mitra yaitu ibu Ermawati yang telah mengikuti kegiatan PKM sampai selesai.

\section{DAFTAR PUSTAKA}

Azadehdel, M. R., Farahbod, F., \& Jamshidinejad, M. A. (2013). The Relationship between Knowledge Sharing, Innovation, and Performance of Manufacturing and Trading Companies in Guilan Province. Interdiciplinary Journal of Contemporary Rsearch in Business, 5(3).

Dirisu, J. I., Iyiola, O., \& Ibidunni, O. S. (2013). Product Differentiation: A tool of competitive advantage and optimal organizational performance (A study of Unilever Nigeria PLC). European Scientific Journal, 9(34).

Drucker, P. F. (2012). Innovation and Entrepreneurship, Practice and Principles (2 ed). (2nd ed.). Erlangga.

Fakhriyyah, D. D., \& Wulandari, Y. (2021). Sosialisasi digital marketing dan inovasi produk pada ukm gula merah guna mempertahankan ekonomi di masa pandemi covid-19. Jurnal Pembelajaran ....

Ikhsani, M. M., Curatman, A., \& Rahmadi, M. S. (2016). Analisis Faktor-faktor Pengaruh Inovasi Produk yang Berdampak pada Keunggulan Bersaing UKM Makanan dan Minuman di Wilayah Harjamukti Kota Cirebon. Jurnal Logika, XVIII(3).

Mahmood, R., Aarakit, S. M., Alarape, A. A., Al-swidi, A. K., Al-Hosam, A., Aminu, I. M., Shariff, M. N. M., Zhongfeng Su, En Xie, and Y. L., Ahmed, I., Ali, G., Ramzan, M., Andersén, J., Anderson, B. S., Eshima, Y., Arbaugh, J., Larry, W., Camp, S., Arief, M., Thoyib, A., ... Me, N. (2013). Entrepreneurial orientation and business performance of women-owned small and medium enterprises in Malaysia: Competitive advantage as a mediator. International Journal of Business and Social Science, 4(1). https://doi.org/10.1177/0266242612455034

Mazzarol, T. (2011). Entrepreneurship and innovation. Readings and cases, second ed. (2nd ed.). Tilde University Press. 
Sulistyo, H. (2016). Asia Pacific Management Review Innovation Capability of SMEs through Entrepreneurship, Marketing Capability, Relational Capital and Empowerment. Asia Pacific Management Review, 21(4), 196-203. 